\title{
POKRAJINA, KRAJINA IN REGIJA V LUČI GEOGRAFSKEGA TERMINOLOŠKEGA SLOVARJA*
}

\author{
Ivan Gams \\ Ulica Pohorskega bataljona I85, SI - 1000 Ljubljana
}

Izvirni znanstveni članek

COBISS 1.01

\section{Izvleček}

Sicer dober Geografski terminološki slovar (2005) sporno enako tolmači termine pokrajina, krajina in regija.

Ključne besede: pokrajina, krajina, regija.

\section{LANDSCAPE TYPES IN THE LIGHT OF THE SLOVENE GEOGRAPHICAL TERMINOLOGICAL GAZETTEER}

\begin{abstract}
In general good and after long time of preparation printed Geographical terminological gazetteer (2005) explaines in same manner the three terms of landscape types, two of the them are different only in Slovene language (pokrajina and krajina), and the last region. Their conception is connected with the concept of the geography in general. In the paper the history of orientation of the geography at the Department of geography at the university of Ljubljana is shorty explained.
\end{abstract}

Key words: two kinds of landscape (pokrajina and krajina), region.

\footnotetext{
* Članek je posvečen osemdesetletnici prof. dr. Darka Radinja, ki je kot predstojnik Oddelka za geografijo FF na začetku sej pedagoškega kolegija prizadeto utemeljeval potrebo, da predavatelji učijo kompleksno in ne dualistično geografijo.

The paper is devoted to the eithy years celebration of prof. Darko Radinja.
} 


\section{UVOD}

Dolgo pričakovani Geografski terminološki slovar (ZRC, 2005, s. 292) je pomembno in dobro delo za slovensko geografsko stroko in njeno izrazoslovje. Zato je toliko bolj škoda, da je v njem sporna razlaga za geografijo pomembnega termina pokrajina.

Geografski terminološki slovar navaja pri geslu pokrajina:«1. splošna geografija: del Zemljinega površja, ki ima glede na prepletanje geografskih pojavov, prvin in součinkovanje geografskih dejavnikov svojski značaj; videz, po katerem se razlikuje od okolice. Sinonim regija. 2. splošna geografija: ozemlje s prevlado ene ali več pokrajinskih prvin. 3. splošna geografija: videz Zemljinega površja, sinonim krajina. 4. splošna geografija: upravna enota višje ravni. Primerjaj: regija«. Po navedenem izpisu iz slovarja ima termin pokrajina v splošni geografiji tri pomene: 1 . ima svojski značaj ali videz , 2. prevladuje ena ali več pokrajinskih prvin, in 3. ima poseben videz zemljinega površja (sinonim krajina). Pri tem slovar dodaja, da so lahko pokrajine tudi upravne enote višje ravni.

Navedeni primer večpomenskosti termina pokrajina v slovar ni zašel pomotoma. Pod naslovom »Vrsta in zgradba slovarja« je v knjigi na strani 20 navedeno načelo: »Strokovni izrazi imajo lahko tudi več pomenov«. Trditev, da ima en in isti termin v stroki več pomenov, je tudi v slovenskem slovaropisju izjemna. O tem se lahko prepričamo, če pregledamo druge terminološke slovarje, ki jih je v zadnjem času izdal Znanstvenoraziskovalni center Slovenske akademije znanosti in umetnosti v Ljubljani. Večpomenskost termina sili učitelje geografije in pisce učbenikov, ki so namenjeni vsem geografom, da uvodoma pojasnijo, katero varianto zastopajo.

\section{GRADIVO}

Iz nemščine v slovenščino prevedeni kvalitetni slovar Duden (1. 2001) ima za termin pokrajina samo eno razlago: »Del Zemljinega površja, ki ima glede na svoj videz in skupno s součinkovanjem tu zastopanih geografskih dejavnikov (vključno človekova dejavnost) značilen značaj, po katerem se razlikuje od svoje okolice«. Prevajalec Dudna, dr. D. Kladnik je tudi eden od urednikov GTS. GTS navaja kot sinonima za pokrajino še področje in območje, ta dva pa imata mnogo širši pomen.

Do večpomenskih terminov v GTS je prišlo zaradi nesporazuma, ali zaradi sodelavcev iz raznih geografskih disciplin, vsekakor pa zaradi neupoštevanja pravice urednikov, da se v primeru različnih razlag odločijo za najustreznejšo varianto in jo s tem normirajo.

Pri besedi pokrajina ima slovar na strani 293 kot primer navedeno »Gorenjska in druge pokrajine«. Toda Gorenjska ni enotna pokrajina!

Poglejmo si na kratko, kako je v povojni slovenski geografiji prišlo do različnih pojmovanj termina pokrajina.

Nestor slovenskih geografov Anton Melik je štiri knjige regionogeografskega opisa slovenskega ozemlja (1954 -1960) izdal pod skupnimi naslovi in podnaslovi "Slovenija, geografski opis, opis slovenskih pokrajin«. A se besede pokrajina v knjigah med tekstom izogiba in jo navadno nadomesti z njenim imenom, ki navadno izvira iz ljudske govorice, dotedanje literature ali javne rabe. Opisov pokrajin ne obravnava po enotni shemi in jih 
praviloma ne deli na naravnogeografski in družbenogeografski del. V ospredju je delitev ozemlja na naravnogeografske enote in družbenogeografski opis prevladuje predvsem pri večjih mestih.

Najstarejša kvantitativna regionalizacija Slovnenije je nastala v letih 1975 - 78 v okviru katedre za fizično geografijo FF. Sodelovali so prof. Stane Marn, geolog S. Buser in drugi. Regije so bile izbrane in omejene s prekrivanjem tematskih kart na foliji v merilu $1: 25.000$ in $1: 100.000$. Kot elaborat raziskovalne teme je bila predana naročniku Raziskovalni skupnosti Slovenije leta 1978 in istega leta tudi v NUK (Gams in sodelavci, 1978). Prva objava s statističnimi podatki za makroregije je bila objavljena leta 1983 v Celovški reviji Klagenfurter Geographische Schiften, zv. 4, s. 13 - 17 (Gams, 1983). To leto je tudi prvič izšel učbenik za geografijo Slovenije v srednji šoli s karto makroregij in 54 mikroregijami (Gams, 1983 in ponatisi). Makroregije, z 22 kazalci za vsako, so bile objavljene v učbeniku Osnove pokrajinske ekologije (Gams, 1986). Najpopolnejša statistična dokumentacije je objavljena v knjigi Geografija Slovenije (Gams, 1998), ki je v rokopisu v založbi (SM) na natis čakala več let. Izpopolnjenih kvantitativnih podatkov, pri katerih je v končni fazi pomagal tudi dr. Matej Gabrovec, je v tabelarnem pregledu pri vsaki mikroregiji 35. Novo kvantitativno regionalizacijo Slovenije s pomočjo GIS je pripravil in objavil Geografski inštitut ZRC SAZU (Perko, 1998).

Termini iz območja regionalizacije so se v slovenski geografiji začeli spreminjati po šestdesetih letih preteklega stoletja, potem ko je bilo na Oddelku za geografijo FF v letih 1958 - 1962 na novo nameščenih pet družbenih in en fizični geograf. ॥V sedemdesetih letih se je pedagoško delo še nadalje drobilo. Koncept enotne geografije se je dokončno osul, zamenjal ga je dualistični, če že ne dezintegracijski« (Radinja, 1974). O poznejšem razvoja študija geografije na ljubljanskem oddelku za geografijo FF priča delež vpisanih študentov magistrskega študija glede na usmeritev v obdobju 2000 - 2004: socialna in politična geografija $36 \%$, regionalna geografija $3 \%$ in fizična geografija $10 \%$ (Klemenčič, M. 2004).

$\mathrm{Ob}$ teh spremembah se je v geografski literaturi pojavil termin krajina. V strokovnih slovarjih navadno pomeni zunanji izgled ali videz pokrajine, kot se pojavlja v umetnosti, ali pejsaž v slikarstvu. S krajino se ukvarja katedra za krajinsko arhitekturo ljubljanske Gradbene fakultete, da ji lahko prilagodi svoje posege. V Geografskem terminološkem slovarju ( ZRC in SAZU, 2003, s. 186) je krajina definirana z besedami:«1. splošna geografija: zgodovinska ali sodobna upravna enota; 2. splošna geografija: glej pokrajina. Geografinja B. Ogorelec (1987), tedaj v službi v Zavodu za regionalno planiranje, kjer je udomačena »krajina«, je v članku z naslovom Za pomensko razmejitev med pokrajino in krajino in proti njej (Geografski vestnik , 1987, s. 133-139) izrazila zaskrbljenost zaradi umikanja besede pokrajina iz rabe v geografiji in njeno zamenjavo s krajino. Geografom predlaga rabo termina geografska pokrajina, ki pomeni »naravnogeografsko in družbenogeografsko kompleksno tvorbo, saj je sinteza pokrajinskih elementov, naravnih in antropogenih, ki medsebojno součinkujejo«. V tem smislu pokrajino tolmači tudi teoretski članek v Geografskem vestniku (Gams, 1985). Pokrajine ne moremo ugotavljati po njenem zunanjem videzu, saj npr. klimatskih, pedoloških ali upravnopolitičnih v pokrajinski podobi ne moremo zaznati 
V Geografskem terminološkem slovarju je sporna tudi trditev, da je regija sinonim za pokrajino. Tej trditvi primerno je v slovarju prilagojena definicija regije (na strani 336), ki da je ..«bolj ali manj enoten del Zemljinega površja ali večje območje, ki zaradi svojskih pokrajinskih sestavin in procesov, njihovega medsebojnega prepletanja, součinkovanja predstavlja značilno pokrajinsko enoto z enakimi naravnimi in/ali družbenimi značilnosti«. V tem slovarju je enako definirana tudi pokrajina! Regija ima tudi v slovenski geografiji več pomenov. Pomeni tudi sedanje in načrtovane upravne enote (npr. koroška regija), območja planiranja (planske regije), poznamo turistične, nerazvite, agrarne, vinogradniške, gričevnate regije itd. Slovenski pravopis (2003) regijo razlaga z besedami: področje, območje, predel. Res pa je, da se v dosedanjih slovenskih geografskih regionalizacijah poleg pokrajine javljata tudi besedi regija in regionalizacija, a kot širši pojem (tudi Gams, 1983). Če bi bili dosledni, bi ta postopek razdelitve ozemlja morali imenovati pokrajinizacija. Toda uvajanje nove besede navadno sprva naleti na odpor, dokler se ga ne navadimo.

V osemdesetih letih preteklega stoletja se je tudi v slovenski geografiji uveljavila računalniška obdelava številčnih podatkov v geografskem informacijskem sistemu (GIS). Avtorji prve regionalizacije te vrste so M. Gabrovec, D. Kladnik, M. Orožen Adamič, M. Pavšek, D. Perko in M. Topole (Perko, 1989). GIS je v regionalizacijo Slovenije sprva prinesel napredek, a tudi pomanjkljivosti (Hrvatin, M., Perko, D. 2005). Dokler je operiral s celicami 1 x $1 \mathrm{~km}$, na manjših kartah Slovenije ni bilo izdvojenih do 1,5 km širokih ravnin v predalpskem, visokogorskem, v gričevnatem, fluviokraškem in kraškem ozemlju. Npr. vrednosti za gostoto prebivalstva ali rabo tal, izračunane za Dovje kot edino večje naselje in katastrsko občino na začetku Zgornje savske doline, so razširjene na ves prostor med Triglavom in vrhom Karavank. Ali: vrednost za rast prebivalstva in poklicno sestavo naselja Mislinja, ki leži ob avtobusni in nekdaj tudi železniški postaji v ozkem dnu zgornje Mislinjske doline so prikazane na prostoru vse katastrske občine, ki obsega gozdnato gorato ozemlje z redkimi samotnimi kmetijami med pohorskim Črnim vrhom in Doličem. Tudi v tem goratem svetu so se namreč v času industrializacije zaposleni intenzivno preseljevali na edino, nekaj sto metrov široko ravnino.

V kotlinah so naselja na robu navadno zgoščena in so mnoge nosilke katastrskih občin, ki segajo daleč v hrib. Pri ročni izdelavi tematskih kart za regionalizacijo Slovenije (Gams, 1998) smo z metodo prekrivanja tematskih kart meje ravninskih (kotlinskih) regij določili in izmerili po izohipsni karti. Tako dobljeni delež ravnin in terasiranih ravnin znaša $17,1 \%$ površja Slovenije. Delež prebivalstva na njih ni točno znan in dosega predvidoma že polovico. Ker so ravnine predvsem v nižjih nadmorskih višinah, si lahko pomagamo z izračuni za višinske pasove. V višinah pod 400 m n.v. je leta 1869 bivalo 64,6 \%, leta 1991 pa že 77,2 \% prebivalcev.. Istočasno je v nadmorskih višinah nad $700 \mathrm{~m}$ delež prebivalstva padel z 6,8 nad 2,4\%. V območjih močne koncentracije prebivalstva, ki ležijo skoraj brez izjeme na ravninskem svetu, živi 354 preb. $/ \mathrm{km}^{2}$ in tu je bivalo $1.1991155 \%$ vseh državljanov RS (Perko, 1998, s. 281, 282). Na bistveno bolj industrializiranih in urbaniziranih ravninah je v pokrajinah bistveno povečana vloga družbenih sestavin, v goratem delu Slovenije, od koder so se izseljevali, pa zmanjšana.

Točnejše izračune za Slovenijo po metodi GIS je prineslo novejše zmanjšanje celic na 25 x 25 m (Hrvatin, M., M.Perko, 2005). 
Enotnosti slovenske regionalne geografije ni v prid, da regije in pokrajine različno imenujemo, naravnogeografske, prirodnoekološke (Perko, 1998), pokrajinsko ekološke in tudi geografske (Gams, 1983).

Regija pomeni večjo ozemeljsko enoto ne glede na njeno vsebino. Da ne bo bilo zamenjav z geografsko pokrajino, bi se ob sedaj predvideni upravni reformi 14 upravnopolitičnih »po krajin« lahko imenovalo upravnopolitične regije. Seveda ima država pravico do imenovanja novih upravno političnih enot, pravica naše stroke pa je, da obdrži svojo terminologijo. Da ima pokrajina $v$ slovenski geografiji drugačen pomen, je bila slovenska vlada pravočasno obveščena.

\section{POMEN KOMPLEKSNE REGIONALNE GEOGRAFIJE}

Imena pokrajina, krajina in regija zadevajo koncepcijo geografske znanosti. Zagovorniki enotne koncepcije geografije in zlasti regionalne geografije vidimo vrednost raziskovanja pokrajine predvsem ob obravnavanju vseh naravnih in družbeno geografskih pokrajinskih dejavnikov, ki v medsebojni odvisnosti določujejo sestavo in ne samo videz pokrajine. Geografske discipline, kot so demogeografija, turistična geografija, agrarna, mestna, naselbinska, socialna, politična, prometna geografija, tiste, ki obravnavajo klimo, prst, vode, kras in druge specialne geografije so po našem mnenju geografske le v toliko, v kolikor svojo tematiko povezujejo z drugimi pokrajinskimi prvinami. Obravnava brez njih je naloga drugih strok, kot so hidrografijo, meteorologijo, ekonomika, statistika in druge prostorske vede, ki so $\mathrm{v}$ javnosti priznane kot samostojne in imajo $\mathrm{v}$ okviru univerz in drugih raziskovalnih organizacij svoje institucije. Delna izjema je geomorfologija. V letih po zadnji svetovni vojni so v njih ob ugodnih pogojih za zaposlitev našli delo tudi absolventi geografije, vprašanje pa je, kako dolgo bo to trajalo.

Kako je lahko vsestranska kvantitativna analiza pokrajine koristna za domačine in sorodne stroke, pa tudi za urade in občinske planerske službe, dokazujeta zlasti regionalni študiji Mirenske doline in moravške občine (Topole, M., 1998,Topole, M., 2003). Obe z metodo GIS ugotavljata med drugim ustreznost ali neustreznost sedanje rabe tal in s tem lajšata iskanje izboljšav, nakazujeta ugodne lege za nove posege itd.

Pokrajine, analizirane s kompleksno regionalno geografsko metodo, so bolj trdožive od tistih, ki jih ugotavljajo samo na podlagi družbenih razmer, saj so naravnogeografski dejavniki časovno stabilnejši. Šele analiza celotnega spleta dejavnikov v pokrajini lahko da odgovor na primer na vprašanje, ali so socialnogeografske spremembe, nastale po zadnji svetovni vojni v vzhodni Evropi in pri nas zaradi novih političnih režimov tolikšne, da lahko govorimo o povsem drugi pokrajini (prim. Urbanc et al., 2004).

Določevanje pokrajinske sestave zahteva obvladovanje metod kompleksne geografije. Naš jubilant prof. dr. Darko Radinja je trditve o tem, da je geografija izrazito antropocentrična, zavrnil z besedami: » V bistvu gre pri takih in podobnih naziranjih pravzaprav za geografski iluzionizem...«(Radinja, 1974).

Vzroke za selitev prebivalstva s hribov v doline in kotline pripisujemo navadno samo urbanizaciji in industrializaciji. Toda $v$ ozadju teh socioloških sprememb je največkrat relief. Ravnina nudi modernim družbenim procesom mnogo boljše pogoje za razvoj kot strmina. 
Spomnimo se samo dveh primerov. Območja odhajanja na dnevno delo v mesta so na ravnini mnogo večja kot na vzpetinah. Izgradnja prometnic je na ravnem mnogo lažje kot v hribih. Kako v njih avtoceste podražijo tuneli, pričajo najnovejše izkušnje.

\section{Literatura}

Duden leksikon Geografija. Izdala in založila Učila international, založba d.o.o. Tržič, 2001 (prevedel Drago Kladnik).

Gams, I., 1978: Kvantitativna prirodnogeografska regionalizacija Slovenije (tipkopis). Narodna in univerzitetna knjižnica Ljubljana.

Gams, I., 1983: Landschaftsoekologische Gliederung Sloweniens. Klagenfurter Geographische Schriften, zv. 4, s. $13-25$.

Gams, I.,1983: Geografske značilnosti Slovenije. Mladinska knjiga, Ljubljana, 183 s.

Gams, I., 1985: Problemi geografskega raziskovanja ekotopov in pokrajinske ekologije v Sloveniji. Geografski vestnik 1985, s.175.

Gams, I., 1986: Osnove pokrajinske ekologije. Filozofska fakulteta. Ljubljana. 175 s.

Gams, I., 1998: Pokrajinsko ekološka sestava Slovenije. Geografija Slovenije. Slovenska matica v Ljubljani, s. $214-243$.

Gams, I., Kladnik, D., Orožen Adamič, M., 1995: Naravnogeografske regije Slovenije. Krajevni leksikon Slovenije. Državna založba Slovenije, 639 s., Ljubljana.

Hrvatin, M., D. Perko, 2005: Differences between 100-meter and 25-meter digital elevation models according to types of relief in Slovenia. Acta geographica Slovenica, 45, s. $7-22$.

Ilešič, S., 1956: Slovenske pokrajine. Geografski obzornik, 3, s. 25 -38.

Ilešič, S., 1979: Pogledi na geografijo. Ljubljana.

Kladnik, D., Lovrenčak, F., Adamič, M., O., 2005 (ur.): Geografski terminološki slovar. ZRC SAZU, $451 \mathrm{~s}$.

Orožen Adamič, M., Perko,D., Kladnik D., 1995: Krajevni leksikon Slovenije. DZS, Ljubljana.

Perko, D., 1998: Prebivalstvo. Geografija Slovenije. Slovenska matica, s. 270 - 309.

Perko, D., 1998: The Regionalization of Slovenia. Naravnogeografska regionalizacija Slovenije. Geografski zbornik, 38, s. 11- 58.

Perko, D., M. Orožen Adamič,1998 : Slovenija-pokrajine in ljudje. MK, 735 s.

Radinja, D., 1977: O kompleksnosti v geografiji in izven nje. Geografski vestnik, 49, s. 25 - 30.

Radinja, D., 1974: Geografija in varstvo človekovega okolja. Geografski vestnik, s.110-120.

Topole, M., 2003: Geografija občine Moravče. ZRC SAZU, ZRC, Ljubljana, 238 s.

Topole, M., 1998: Mirnska dolina. Regionalna geografija porečja Mirne na Dolenjskem. ZRC, Ljubljana, 175.s.

Urbanc, M., 2004, Printsmann,A., Palang H., Skowronek, E., Woloszyn, W, Konkoly Gyuro, E., : Coprehension of rapidly transforming landscapes of Central and Eastern Europe in the $20^{\text {th }}$ century. Geografski zbornik, 44, 2, Ljubljana, s. $101-131$. 


\section{LANDSCAPE AND REGION IN THE ASPECT OF THE NEW SLOVENIAN GEOGRAPHICAL TERMINOLOGICAL GAZETTEER \\ Summary}

The new and in general good Slovenian geographical terminological dictionary (with 8922 geographical terms), printed by Geographical Institute of the ZRC SAZU at Ljubljana in the year 2005, explains by the same manner three different terms of landscape existed in the Slovene geography. One of them, region, has wider notion. For the first two of them exist different names only in the Slovene language (pokrajina, krajina) The first one is used in the regional geography (interpreting a landscape as an unique interconnected system of all natural and social factors), and the second one, which considers mostly the social factors. The celebrated professor Darko Radinja has confronted the dualistic geography already in the time when he headed the Geographical department at the Philosophical Faculty at Ljubljana. The value of the complex geography he has proofed also by his research work. 